\title{
Original Article EFFECT OF PERCUTANEOUS AND OPEN TENOTOMY ON CONTINUITY OF TENDOACHILLIS IN RELAPSED CLUBFOOT
}

\author{
Khairy H.M, Elzohairy M.M, El-aidy S.M, Nusayr A.N. \\ Department of Orthopedic Surgery, Faculty of Medicine, Zagazig University, \\ Zagazig, Egypt
}

Corresponding Author:

Abdulsalam Nusayr Salim

Nusayr

Department of Orthopedic

Surgery, Faculty of

Medicine, Zagazig

University

abseenasser3@gmail.com

$\begin{array}{ll}\text { Submit Date } & 2019-01-03 \\ \text { Revise Date } & 2019-03-1 \\ \text { Accept Date } & 2019-03-04\end{array}$

\begin{abstract}
Background: Tenotomy of tendon Achilles is one of the major components of Ponseti method and necessary to complete correction in about 80 to $90 \%$ of patients, it is safely procedure can be done in outpatient office as percutaneous technique under local anesthesia or in operative room under general anesthesia as mini-open technique. This study was designed to evaluate effect of tendoachillis tenotomy either percutaneous or open on continuity of tendoachillis by open evaluation in
\end{abstract} relapsed club foot.

Patient \& method: This study was conducted on 18 individuals. They were divided into 2 equal groups: Group I: containing 9 patients both sex had previously percutaneous tenotomy is done and Group II: 9 patients both sex had previously open tenotomy is done.

Results: percutaneous technique found easy dissection in 6 patients (66.7\%) and difficult dissection in 3 patients (33.3\%) and continuity found central and regular contour in 7 patients (77.8\%) and fibrotic mass in 2 patients (22.2\%), open technique found easy dissection in 5 patients (55.6\%) and difficult dissection in 4 patients (44.4\%) and continuity found central and regular contour in 5 patients (55.6\%) and fibrotic mass in 4 patients $(44.4 \%)$,

Conclusion: the techniques tenotomy of tendoachillis had no effect on continuity of tendoachillis either open or closed techniques in management of club foot.

Keywords: clubfoot, tenotomy, tendon Achilles, Ponseti method.

\section{INTRODUCTION}

C ongenital or idiopathic clubfoot is a deformity resulting from a complex 3dimensional foot misalignment that is caused by a combined hindfoot equinus and varus associated with forefoot cavus and adduction. Its estimated population incidence is 1 per thousand live births in most western countries, but it may vary from 0.39 per thousand in Chinese people to 6.8 per thousand among Polynesians, and despite the unknown etiology, both genetic and racial factors may be involved [1].

The aim of congenital clubfoot treatment is to achieve a functional, painless, plantigrade, and flexible foot. Regardless of the etiology, orthopaedic management is intended to correct the deformities, and over time the preferred treatment has ranged from predominantly conservative nonsurgical methods to surgical methods. In the last 10 years, the technique described by Ponseti has become increasingly popular, with many favorable reports [2].

The Ponseti technique involves weekly manipulations and serial casting to allow collagen relaxation and atraumatic remodeling of joint surfaces without fibrosis and scarring from surgical releases. The order of correction with serial casting 
progresses from addressing the midfoot cavus to forefoot adduction to hindfoot varus, then finally to hindfoot equinus. If a residual equinus deformity is still present, a TAL is performed prior to the final cast application. The TAL is needed in about 85 $\%$ of cases [3].

Achilles tenotomy is an important step in the serial manipulation casting management of congenital clubfoot. Intentionally avoiding this stage may lead either to arocker-bottom deformity of the foot due to excessive dorsiflexion efforts or to incomplete hind-foot correction [4].

Prerequisites for tenotomy are achieving a forefoot abduction of $70^{\circ}$ or Pirani's midfoot score of less than 1 with coverage of talar head, All these parameters ensure that calcaneum is rotated laterally from the undersurface of the talus and is ready to evert and extend. Indications of tenotomy are inability to achieve dorsiflexion of $15^{\circ}$ by one finger pressure at the midfoot or Pirani's hindfoot score more than one [5].

Healing of the tendon has been classically described as involving extrinsic or intrinsic factors or a combination of the two. In an extrinsic process, the gap is invaded by fibroblasts, and the repair leads to the formation of a fibrous scar with adhesions that favour the blood supply but may interfere with the sliding mechanism, and may also represent a mechanical shortcoming. In an intrinsic repair process, a cascade of cellular and biochemical events takes place; fibroblast migration tends to proceed in an orderly fashion, and thus tendon tissue is regenerated in a fetal like process [6]

Ponseti and many clinicians have traditionally performed TAL in the clinic . The benefits of performing the procedure in an outpatient office setting include decreased cost, no general anesthesia, and immediate treatment [7].
Other surgeons choose to perform the TAL in an OR setting. The benefits include: improved safety, better control of the procedure for the surgeon, better ability to manage complications, and improved ability to safely guide a resident through the procedure [8].

The aim of this study to evaluate effect of tendoachillis tenotomy either percutaneous or open on continuity of tendoachillis by open evaluation in relapsed club foot.

\section{PATIENT AND METHOD}

This study is cross-sectional study and was conducted in Orthopedic Surgery Department of Faculty of Medicine, Zagazig University Hospitals. Written consent was obtained from all subjects, from January to August at 2018. The work has been carried out in accordance with The Code of Ethics of the World Medical Association (Declaration of Helsinki) for studies involving humans.

The study included 18 individuals divided into two groups Group I: 9 patients both sex ( 7 male and 2 female) and age range from 11 to 24 months had previously percutaneous tenotomy was done. And Group II: 9 patients both sex ( 2 male and 7 female) and age ranged from 12 to 24 month had previously open tenotomy was done.

The inclusion criteria were included children who have relapsed clubfoot with tenotomy done either open or percutaneous and age ranged from 6 to 24 month, exclusion criteria were included paralytic cases.

\section{Methods of assessment:}

Clinically by intraoperative observation

\section{RESULTS}

Eighteen patients of relapsed club foot were enrolled in this study, 9 male $(50 \%)$ and 9 female $(50 \%)$ their age ranged from minimum 11 month to maximum 24 month $($ Mean \pm SD $)=(16.77 \pm 5.4), \quad$ primary tenotomy is done at age ranged from 2 
month to 9 month (Mean \pm SD) $=($ $4.47 \pm 2.02)$, secondary tenotomy is done at age ranged from 11 month to 24 month $($ Mean \pm SD $)=(16.77 \pm 5.48)$, in Orthopedic Surgery Department of Faculty of Medicine, Zagazig University Hospitals. consent was obtained from all subjects, from January to Augustus at 2018.

In this study, we found no significant difference between groups of study in both techniques according to age of primary tenotomy as seen in table (1) and figure(1,2,3), on comparison between two features of tendon Achilles intraoperative:

1) Regarding adhesion to bed or surrounding structure:
- Percutaneous group: we found easy dissection in 6 patients $(66.7 \%)$ and difficult dissection in 3 patients $(33.3 \%)$.

- Open group: we found easy dissection in 5 patients $(55.6 \%)$ and difficult dissection in 4 patients $(44.4 \%)$.

2) Regarding to continuity:

- Percutaneous group: we found central and regular contour in 7 patients $(77.8 \%)$ and fibrotic mass in 2 patients $(22.2 \%)$.

- Open group: we found central and regular contour in 5 patients $(55.6 \%)$ and fibrotic mass in 4 patients (44.4\%) which found no significant association between groups of study as see in table (3).

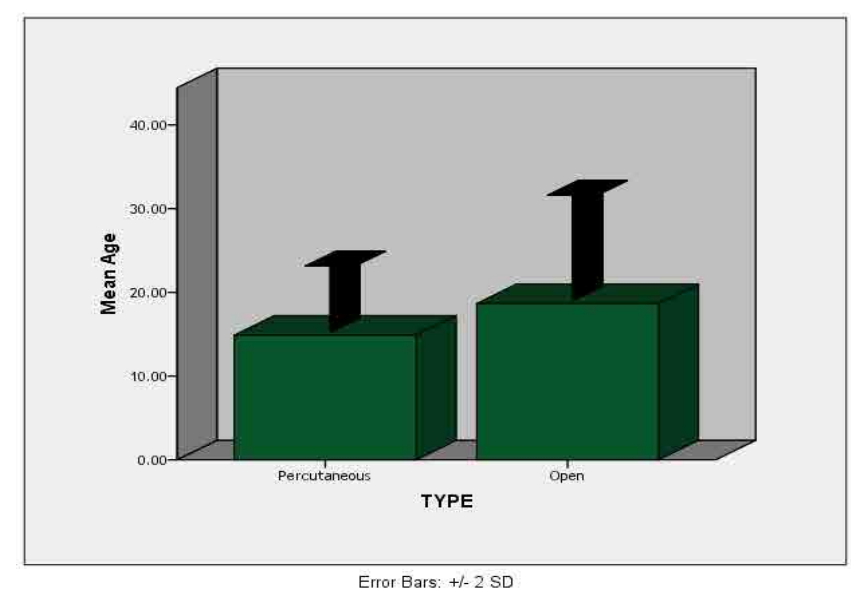

Fig 1 Comparison between different techniques
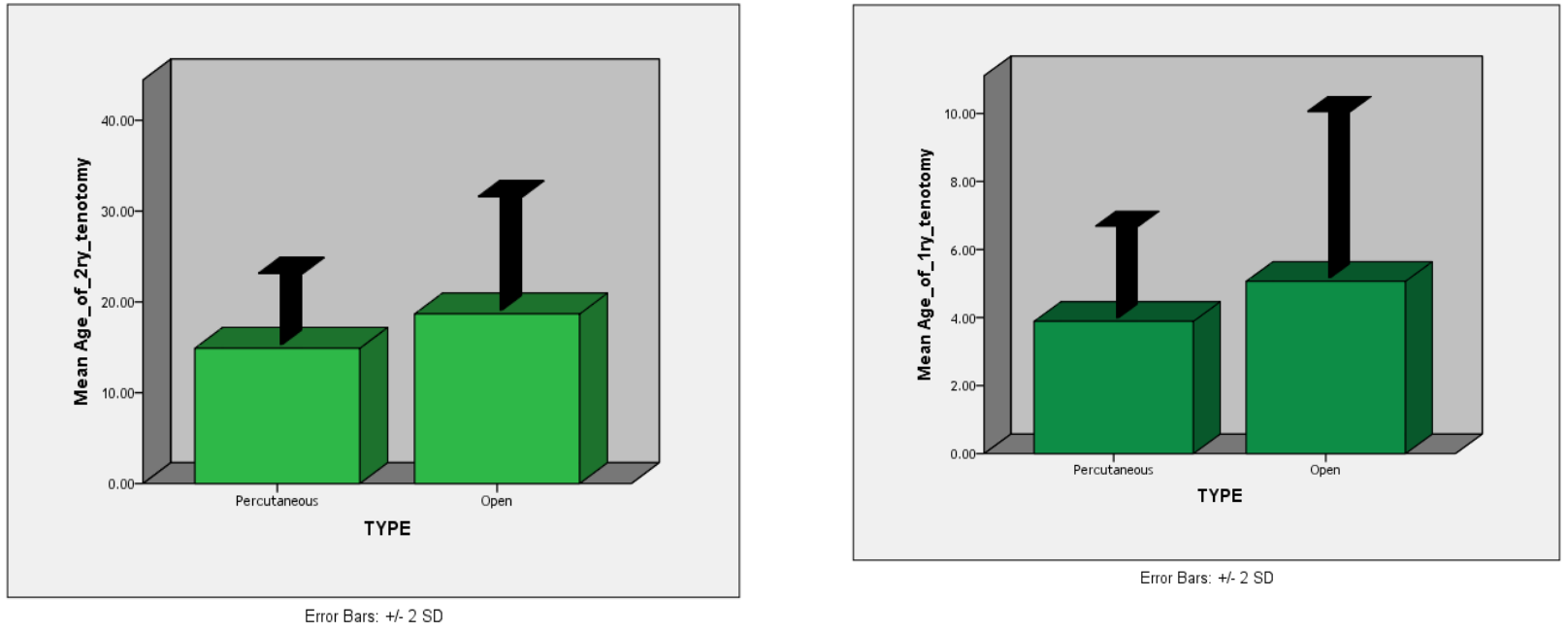

Fig 2, 3 Comparison between different techniques in age of 1ry and 2rytenotomy 
Table 1 distribution of age in different techniques:

Percutaneous technique is done more in younger age group than open technique, yet there is statically no significant difference regarding choice of technique for age.

\begin{tabular}{|l|c|c|c|c|}
\hline & $\begin{array}{c}\text { Percutaneous } \\
(\mathbf{N}=9)\end{array}$ & $\begin{array}{c}\text { Open } \\
(\mathbf{N}=9)\end{array}$ & $\begin{array}{l}\text { t/ Mann } \\
\text { Whitney }\end{array}$ & P \\
\hline Age & $14.88 \pm 3.98$ & $18.66 \pm 6.32$ & -1.516 & 0.149 \\
\hline Age_of_1ry_tenotomy & $\mathbf{3 . 8 8} \pm 1.36$ & $\mathbf{5 . 0 6} \pm 2.2$ & $\mathbf{- 1 . 2 5 5}$ & $\mathbf{0 . 2 2 8}$ \\
\hline Age_of_2ry_tenotomy & $\mathbf{1 4 . 8 8} \pm 3.98$ & $\mathbf{1 8 . 6 6} \pm 6.32$ & $\mathbf{- 1 . 5 1 6}$ & $\mathbf{0 . 1 4 9}$ \\
\hline
\end{tabular}

Table 2 Clinical and personal characters:

This table show clinical and personal character as sex distribution and side affected and other disease associated which found 2 patients of percutaneous group associated with other disease and 4 patients in open group associated with other disease.

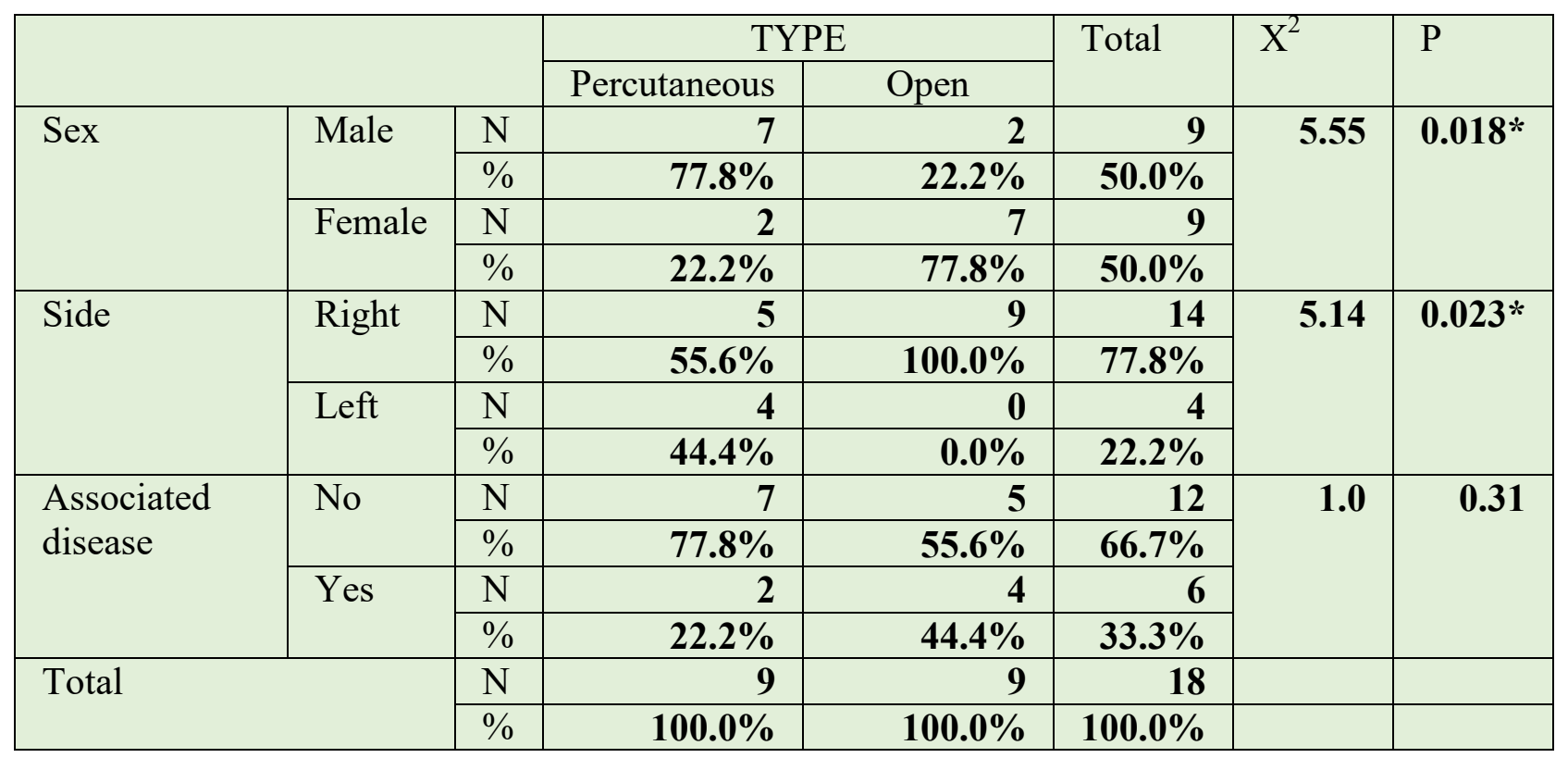

In both group of study: Percutaneous technique was significantly associated with male (77.8\%) and left side (44.4\%). 
Table (3): Features of tendon Achilles comparison by naked eye in studies group:

This table shows two features of tendon Achilles intraoperative by naked eye show regarding adhesion to bed or surrounding structure:

Percutaneous technique found easy dissection in 6 patients $(66.7 \%)$ and difficult dissection in 3 patients $(33.3 \%)$ and continuity found central and regular contour in 7 patients $(77.8 \%)$ and fibrotic mass in 2 patients $(22.2 \%)$.

Open technique found easy dissection in 5 patients $(55.6 \%)$ and difficult dissection in 4 patients (44.4\%) and continuity found central and regular contour in 5 patients $(55.6 \%)$ and fibrotic mass in 4 patients $(44.4 \%)$,

\begin{tabular}{|c|c|c|c|c|c|c|c|}
\hline \multicolumn{5}{|c|}{ TYPE } & \multirow[t]{2}{*}{ Total } & \multirow[t]{2}{*}{$X^{2}$} & \multirow[t]{2}{*}{$\mathrm{P}$} \\
\hline & & & Percutaneous & Open & & & \\
\hline \multirow{4}{*}{$\begin{array}{l}\text { Adhesion } \\
\text { to bed }\end{array}$} & \multirow[t]{2}{*}{ Easy } & $\mathrm{N}$ & 6 & 5 & 11 & \multirow[t]{4}{*}{0.23} & \multirow[t]{4}{*}{0.62} \\
\hline & & $\%$ & $66.7 \%$ & $55.6 \%$ & $61.1 \%$ & & \\
\hline & \multirow[t]{2}{*}{ Difficult } & $\mathrm{N}$ & 3 & 4 & 7 & & \\
\hline & & $\%$ & $33.3 \%$ & $44.4 \%$ & $38.9 \%$ & & \\
\hline \multirow[t]{4}{*}{ Continuity } & \multirow[t]{2}{*}{ Central } & $\mathrm{N}$ & 7 & 5 & 12 & \multirow[t]{4}{*}{1.0} & \multirow[t]{4}{*}{0.31} \\
\hline & & $\%$ & $77.8 \%$ & $55.6 \%$ & $66.7 \%$ & & \\
\hline & \multirow[t]{2}{*}{ Fibrotic } & $\mathrm{N}$ & 2 & 4 & 6 & & \\
\hline & & $\%$ & $22.2 \%$ & $44.4 \%$ & $33.3 \%$ & & \\
\hline \multirow{2}{*}{\multicolumn{2}{|c|}{ Total }} & $\mathrm{N}$ & 9 & 9 & 18 & & \\
\hline & & $\%$ & $100.0 \%$ & $100.0 \%$ & $100.0 \%$ & & \\
\hline
\end{tabular}

Found no significant difference between open and percutaneous techniques on continuity of tendon Achilles in both groups of study.

\section{DISCUSSION}

Clubfoot is one of the most common congenital deformities in pediatric orthopedics. It is a congenital dysplasia of all musculoskeletal structures (muscles, tendons, ligaments, osteoarticular and neurovascular structures) distal to the knee. The foot presents equinus, cavus, varus and adducted positions and is supinated. Clubfoot occurs in about 1 in 1,000 newborns. Males are affected about twice as often as females. Treatment can be carried out by a range of healthcare providers and can generally be achieved in the developing world with few resources [9].

Achilles tenotomy is an important step in the serial manipulation casting management of congenital clubfoot. Intentionally avoiding this stage may lead either to arocker-bottom deformity of the foot due to excessive dorsiflexion efforts or to incomplete hind-foot correction [4].

This study aims to evaluate effect of tendoachillis tenotomy either percutaneous or open on continuity of tendoachillis by open evaluation in relapsed club foot.

In our study, total number of patients is eighteen divided into two groups; one group (9 patients) done tenotomy by percutaneous and other group (9 patients) by open, male to female ratio is equal in this study.

In this study, the youngest infant was 11 months, while the oldest was 24 months with range 14 months; this is close to that reported by Agarwal S, et al [10]; in his study who choose children younger than 24 months for their study.

Laterality: As regards laterality, the ratio of bilateral to unilateral clubfoot is $3.6: 1.3$ (27.7\% bilateral and $72.2 \%$ unilateral). 5 $(27.7 \%)$ of our cases were bilateral and 13 
(72.2\%) were unilateral (13right and 5 left sided).

In our study, age of primary tenotomy ranged from 70 days to 9 months with range 4 month, this is close to that reported by Niki H.et al [6] in his study who choose children was performed tenotomy 10.4 weeks (mean; range 8-16) weeks after birth.

In our study, evaluating adhesion to bed or surrounding structure of tendon Achilles was intraoperative by naked eye it was found easy dissection from surrounding structure is 6 of 9 patients $(66.7 \%)$ and difficult to dissection is 3 of 9 patients $(33.3 \%)$ in percutaneous technique and continuity of tendon Achilles was found central and regular contour is 7 of 9 patients $(77.8 \%)$ and fibrotic mass is 2 of 9 patients $(22.2 \%)$ in percutaneous technique and in open technique found easy dissection is 5 of 9 patients $(55.6 \%)$ and difficult dissection is 4 of 9 patients $(44.4 \%)$ in open technique and was found central and regular contour is 5 of 9 patients $(55.6 \%)$ and fibrotic mass is 4 of 9 patients $(44.4 \%)$ in open technique which found No significant association in both groups of study.

In our study, all studied group were with good continuity of tendon Achilles, Ponseti and others clinically observed that the continuity of the Achilles tendon is restored in three weeks, reported three phases of healing (inflammatory, proliferative and remodeling) within the gap zone of a divided Achilles tendon in children with clubfeet with the healing being complete by 12 weeks in the majority of children under the age of 24 months. At six weeks a bulbous mass was still present within the gap. In their patients the transition from regenerating to normal tendon appeared between six and 12 weeks, when the new fibers became indistinguishable from the original tendon $[11,12]$.

Our study corroborates with the studies carried out by the following authors:
In study of Niki H. et al [6], The subjects were 23 patients with 33 clubfeet. Achilles tenotomy was performed at mean 10.4 (8-16) weeks after birth. Dynamic and static ultrasonography was performed before tenotomy and at 1,2, 3, 4, 6, 8, and 12 weeks as well as at 4, 6, 12, 18, and 24 months after tenotomy. Concluded to sequential changes in Achilles tendon healing for up to two years after tenotomy were observed ultrasonographically. Gliding was noted within four weeks. At one year, the thickness of the tendon did not differ much from that of the normal tendon. At two years after tenotomy, slight irregularity of the internal structure persisted when compared with the non affected side.

In study of Agarwal A, et al,[13] in an ultrasonographic study of Achilles tendon in congenital clubfeet before and after tenotomy on 39 feet of 27 cases found functional continuity of the Achilles tendons 4 weeks after tenotomy using clinical and ultrasonographic methods.

In study of Saini R, et al,[14] studied the regeneration potential of Achilles tendon after percutaneous tenotomy in 34 clubfeet treated by Ponseti's technique clinically and using MRI at 6 weeks and 6 months. The study revealed continuity of the tendon in all cases at the end of 6 weeks and 6 months of the tenotomy. They concluded that tendoachilles does regenerate following percutaneous tenotomy, used in the correction of clubfoot using Ponseti's technique.

In study of Kowalczyk B, et al, [15] studied early results of conservative treatment in congenital clubfeet with percutaneous tenotomy of Tendo Achilles in 10 children (16 feet). On follow up found that all Achilles tendons regenerated. They concluded that the percutaneous tendon Achilles tenotomy is a safe and valuable procedure which allows to avoid early surgery in $88 \%$ of clubfeet. 
These studies have not reported any complication of Tendon Achilles tenotomy in these older children apart from the less equines correction

\section{CONCLUSION}

In our study conclusion to the techniques tenotomy of tendoachillis had no effect on continuity of tendoachillis either open or closed techniques in management of club foot.

\section{Declaration of interest}

The authors report no conflicts of interest. The authors alone are responsible for the content and writing of the paper.

Funding information

None declared

\section{REFERENCES}

[1] Dobbs MB and Gurnett CA. (2009): Update on clubfoot: etiology and treatment. ClinOrthopRelat Res;467:1146-1153.

[2] Bor N, Coplan JA and Herzenberg JE. (2009): Ponseti treatment for idiopathic clubfoot: minimum 5-year followup. ClinOrthop Relat Res.467:1263-1270.

[3] Rhett $M$, William $H$, Brian $S$, et al (2016):A mini-open technique for Achilles tenotomy in infants with clubfoot, $J$ Child Orthop 10:19-23.

[4] Lebel E, Karasik M, Bernstein-Weyel M, et al (2012): Achilles tenotomy as an office procedure: safety and efficacy as part of the Ponseti serial casting protocol for clubfoot. $J$ PediatrOrthop 32:412-415.

[5] Scher DM, Feldman DS, Bosse JP, et al (2004): Predicting the need for tenotomy in the Ponseti method for correction of clubfeet. $J$ Pediatr Orthop ; 24:349-352.

[6] Niki $H$, Nakajima $H$, Hirano $T$, et al (2013): Ultrasonographic observation of the healing process in the gap after aPonseti-type Achilles tenotomy for idiopathic congenital clubfoot at two-year follow-up, J OrthopSci; 18:70-75.
[7] Samir S and Musaab MA. (2015): Safety and Efficacy of Achilles Tenotomy under Local Anaesthesia: as Part of the Ponseti Clubfoot Management - Experience at the Sudan clubfoot clinic,Gezira Journal of Health Science, Volume 11(2).

[8] Parada SA, Baird GO, Auffant RA, et al (2009): Safety of percutaneous tendoachilles tenotomy performed under general anesthesia on infants with idiopathic clubfoot. $J$ Pediatr Orthop 29:916-919.

[9] Gibbons PJ and Gray K (2013):Update on clubfoot, Journal of Paediatrics and Child Health 49; 434-437.pub med.

[10] Agarwal S, Suresh B, Mathew V, et al (2017): Functional outcome of tendoachilles following Ponseti's tenotomy for treatment of congenital talipes equinovarus in children older than two years: International Journal of Research in Orthopaedics; 3(5): 1057-1061.

[11] Herzenberg JE, Radler C and BorN, (2002):Ponseti versus traditional methods of casting for idiopathic clubfoot. $J$ PediatrOrthop;22:517-21.

[12] Mangat KS, Kanwar R, Johnson K, et al (2010): Ultrasonographic phases in gap healing following Ponseti type Achilles tenotomy. J Bone JtSurg Am 92:1462-1467.

[13] Agarwal A, Qureshi NA, Kumar P, et al (2012): Ultrasonographic evaluation of Achilles tendons in clubfeet before and after percutaneous tenotomy. Journal of orthopaedic surgery (Hong Kong) 20:1:pg 71-4.

[14] Saini R,Dhillon MS, Tripathy SK, et al (2010): Regeneration of the Achilles tendon after percutaneous tenotomy in infants: a clinical and MRI study. Journal of pediatric orthopedics. Part B 19:4 pg 344-7.

[15] Kowalczyk B, Lejman T, Sułko J, et al (2004): Percutaneous tenotomy of achilles tendon in the treatment of congenital clubfeet a preliminary report. Chirurgia narzadów ruchu i ortopedia polska 69:5 :pg 335-337.

To cite this article: Khairy HM, Elzohairy MM, El-aidy SM, Nusayr AN.. Effect of Percutaneous and Open Tenotomy on Continuity of Tendoachillis in Relapsed Clubfoot, Egypt.ZUMJ 2019; 25 (3);278284, DOI: 10.21608/ZUMJ.2019.7004.1011. 